\title{
Expectativas de Pacientes acerca do Atendimento Psicológico em um Serviço-Escola: da Escuta à Adesão
}

\author{
Rita Aparecida Nicioli Cerioni \\ Universidade Paulista, SP, Brasil.
}

\author{
Eliana Herzberg \\ Universidade de São Paulo, SP, Brasil.
}

\begin{abstract}
Resumo: Este artigo objetiva apresentar e discutir as expectativas acerca do atendimento psicológico de pessoas que se inscreveram em um serviço-escola de uma universidade do interior do estado de São Paulo, e analisar em que medida a escuta e compreensão dessas expectativas podem favorecer a adesão ao processo psicoterápico. Foram realizadas entrevistas de triagem com dez participantes que aguardavam na lista de espera para atendimento psicológico e análise documental dos prontuários um ano após a triagem para verificar a adesão. Os resultados foram tratados segundo a análise de conteúdo enfocando queixa manifesta, queixa latente, expectativas, adesão e desistência e discutidos a partir dos pressupostos psicanalíticos. Verificou-se uma adesão positiva ao encaminhamento proposto, indicando que a escuta e compreensão das expectativas dos usuários do serviço-escola de Psicologia podem enriquecer o sentido da busca por atendimento psicológico. As implicações deste estudo dizem respeito ao estabelecimento de uma escuta mais acurada das necessidades e expectativas dos pacientes na triagem e um maior cuidado por parte dos supervisores e estagiários em relação a essa escuta, possibilitando uma redução do hiato muitas vezes existente entre as expectativas das pessoas que buscam atendimento psicológico e as dos estagiários de Psicologia.

Palavras-chave: Expectativas, Triagem Psicológica, Serviço-Escola, Abandono de Tratamento.
\end{abstract}

\section{Patient's Expectations Regarding Psychological Care in Psychological Clinics: from Listening to Engaging}

\begin{abstract}
This paper aims to present and to discuss expectations about psychological care of people who signed up for a psychological clinic at an university in the state of São Paulo, and to analyze to what extent the listening and understanding of these expectations may favor adherence to the psychotherapy process. Screening interviews were performed with ten participants from a waiting list for psychological attention and documentary analysis of records one year after the screening was conducted to verify adherence. The results were treated according to content analysis focusing on manifest complaint, latent complaint, expectations, adherence and dropouts as well as discussed from psychoanalytic assumptions. There was a positive adherence to the proposed referral, indicating that listening and understanding the expectations of users from the psychology clinic can enrich the sense of seeking psychological treatment. Implications of this study relate to the establishment of a closer listening to the needs and expectations of patients in screening and of greater caution from the supervisors and interns in relation to this listening, enabling a reduction of the gap that often exists between people's expectations seeking for psychological counseling and psychology interns' expectations.
\end{abstract}

Keywords: Expectations, Psychological Screening, Psychological-Clinic, Treatment Dropout. 


\title{
Expectativas de Pacientes sobre la Atención Psicológica del Servicio Escuela: de la Escucha a la Adhesión
}

\begin{abstract}
Resumen: Este artículo presenta y discute las expectativas sobre atención psicológica de las personas que se inscribieron en un Servicio Escuela de una universidad del interior del estado de São Paulo, y analiza en qué favorecen la escucha y la comprensión a la adhesión al proceso psicoterápico. Se entrevistó a diez participantes que estaban en lista de espera para tener atención psicológica y fue hecho un análisis de las fichas, un año después de haberse hecho la selección, para constatar la adhesión. Los resultados se trataron según el análisis de contenido enfocando en la queja manifiesta, la queja latente, las expectativas, la adhesión y el desistimiento, a partir de suposiciones psicoanalíticas. Se comprobó que hubo adhesión positiva, indicando que la escucha y la comprensión de las expectativas de los usuarios del Servicio Escuela de Psicología pueden enriquecer la búsqueda por atención psicológica. Las implicaciones del estudio se refieren al establecimiento de una escucha precisa de las necesidades y expectativas de los pacientes en la selección, y al cuidado mayor de supervisores y pasantes con relación a esa escucha, haciendo posible reducir el hiato que muchas veces existe entre las expectativas de las personas que buscan atención psicológica, y las de los pasantes de psicología.
\end{abstract}

Palabras clave: Expectativas, Selección Sicológica, Servicio Escuela, Abandono de Tratamiento.

\section{Introdução}

A procura por atendimento psicológico parece ser, na sua grande maioria, motivada por um sofrimento, um momento de dor, de dúvida e muitas vezes de esperança. Ligar em um serviço, se inscrever para atendimento psicológico caracterizam um pedido de ajuda. Nos serviços-escola, via de regra, há listas de espera como mostram os estudos de Ancona-Lopes (1981), Campezatto e Nunes (2007), Guerrelhas e Silvares (2000), Herzberg e Chammas (2009) e Peres (1997). No serviço-escola em que esse estudo foi realizado, os pacientes frequentemente entram em contato para saber em quanto tempo serão chamados. Há explicitamente um desejo pelo atendimento psicológico. No entanto, dos pacientes que são atendidos em triagem e encaminhados à psicoterapia, um alto índice não adere ou desiste do atendimento nas primeiras entrevistas.

Alguns estudos consideram abandono, tanto pessoas que nem iniciam a psicoterapia, quanto aquelas que a interrompem após um número de sessões, por considerarem ter havido uma melhora e não necessitarem mais de atendimento (Renk, \& Dinger, 2002; Bueno et al., 2001). Outros consideram abandonantes aqueles que não retornaram após a primeira consulta (Garfield, 1989; Lhullier, Nunes, \& Horta, 2006; Maramba, \& Hall, 2002; Melo, \& Guimarães,
2005). O critério de abandono adotado neste estudo é o de Bueno et al. (2002), que considera abandono o não comparecimento dos pacientes que passaram por acolhimento (triagem) e também aqueles que iniciaram psicoterapia e não deram continuidade.

Estudos apontam que há um consenso de que os serviços-escola das faculdades de Psicologia existem para cumprir três objetivos: ensino, formando profissionais para contextos regionais e culturais diversificados, que se integrem à rede pública e privada de saúde, às comunidades carentes, às organizações e às instituições e extensão; atendimento à comunidade promovendo, a partir de atuação fundamentada em conhecimentos teóricos e em princípios éticos e humanistas, a melhoria da qualidade de vida e o bem-estar individual e coletivo; e pesquisa, desenvolvendo estudos de relevância social e científica (Ancona-Lopez, 2005; Campezatto, \& Nunes, 2007; Melo-Silva, Santos, \& Simon, 2005; Romaro, \& Capitão, 2003; Silvares, 1998).

É geralmente a partir do sétimo semestre, ou quarto ano do curso de Psicologia, que os alunos iniciam suas atividades nos serviços-escola, e encontram finalmente uma prática próxima daquilo que geralmente almejam desde o ingresso na faculdade: 0 contato com o paciente. O estagiário é um dos atores que compõe o cenário de um serviço-escola de Psicologia. É necessária uma atitude ativa por parte do 
estagiário no processo, o que significa que ele não deve apenas absorver passivamente o que aprende, as técnicas, as teorias, mas sim deve reformular sua condição profissional, seu saber específico e em uma relação com quem atende e quem o supervisiona (Milagre, \& Dias, 2012).

Nas práticas de supervisão pode-se perceber que esse é um momento de angústia para os alunos, agora estagiários, pois essa busca pela prática é sempre, ou na maioria das vezes, uma busca idealizada. A realidade que se apresenta é um caminho difícil, cheio de percalços e frustrações. Estar diante do outro, escutando seu sofrimento e suas necessidades, coloca o estagiário frente às limitações de um saber, não necessariamente teórico, mas sobre esse humano que se manifesta como um enigma a ser decifrado. Pelo menos é assim que alguns estagiários se manifestam na supervisão, como se eles tivessem que desvendar os motivos e as soluções para o sofrimento humano com base em teorias psicológicas

Ávidos por textos que traduzam exatamente o paciente que eles atendem, os estagiários buscam respostas, insights que os ajudem a compreender e auxiliar aqueles que procuram os serviços, para que assim se sintam competentes no que fazem. Em muitas situações, a ansiedade do aluno em aprender se sobrepõe em relação à necessidade daqueles que procuram atendimento psicológico. É nessa prática psicológica que se abre a possibilidade de repensar a teoria, contextualizá-la e ao mesmo tempo atualizá-la (Morato et al., 2000), emergindo a urgência de refletir sobre o alto índice de desistência e ações que possam favorecer o engajamento das pessoas que buscam atendimento psicológico nestes contextos a partir de uma aproximação entre suas expectativas e as dos estagiários.

Segundo Fiorini (2008), de cada 100 pacientes que comparecem às primeiras entrevistas em instituições, entre 30 e 65 abandonam de imediato o processo. Afirma que o fenômeno da desistência é multifatorial, devendo-se considerar tipo de paciente, grupo familiar, condições culturais e socioeconômicas, características da instituição e do terapeuta, destacando a importância da condução da primeira entrevista na determinação da adesão ou desistência em relação à psicoterapia. Esta primeira entrevista é a triagem psicológica.

Frequentemente a triagem é realizada de modo breve e superficial podendo levar ao abandono em função de um encaminhamento pouco indicado à demanda (Herzberg, \& Chammas, 2009). O abandono precoce do tratamento é um entrave importante no desenvolvimento da aliança terapêutica. Refletir sobre o abandono, e não apenas aceitá-lo como um problema ou resistência do paciente, permite o aprimoramento técnico dos terapeutas, especialmente dos iniciantes, como é o caso dos estagiários (Benetti, \& Cunha, 2008).

Estudos mostram que a triagem é por si só uma intervenção psicológica, cujo significado é dado no campo relacional que se estabelece entre paciente e o profissional (Ancona-Lopez, 1996; Merg, 2008; Perfeito, \& Melo, 2004). Um momento de acolhimento da demanda de cada um, e não de resposta. Cria-se, assim, um efeito de escuta dessa demanda que permite que o paciente possa se ver responsável por ela. Falando de si à instituição, recebe de volta uma pergunta sobre o que quer, o que deseja, o que espera (Salinas, \& Santos, 2002). Na modalidade de triagem em que a proposta é interventiva, a partir da entrevista clínica proposta por Bleger (1998), o psicólogo se coloca disponível às diferentes demandas. Propõe que as entrevistas se transformem em um processo que permita ao paciente a oportunidade de engajar-se no seu próprio atendimento, responsabilizando-se por seus problemas e participando ativamente na decisão acerca do encaminhamento (Ancona-Lopez, 2005).

Isto significa que a triagem interventiva não visa apenas coleta de dados, identificação da demanda e encaminhamento adequado. Além destas funções, constitui-se também como cuidado, abrindo sua escuta para aquilo que o paciente tem a dizer, o que o mobilizou a procurar ajuda psicológica (Rocha, 2011). Interventiva porque tem o objetivo de oferecer às pessoas que buscam atendimento psicológico uma posição de quem pode se beneficiar desse processo, se apropriar de sua demanda, e não só o de oferecer o lugar de um objeto de estudo (Barbieri, 2008).

Escutar, em psicanálise, é escutar o desejo. Como explicitam Macedo e Falcão (2005): "A situação analítica é, por excelência, uma situação de comunicação: nela circulam demandas, nem sempre lógicas ou de fácil deciframento, mas as quais, em seu cerne, comunicam o desejo e a necessidade de ser escutadas" (p. 65). Neste caso, a escolha pelo verbo escutar não é aleatória. Entende-se que há uma diferença importante entre ouvir 
e escutar. De acordo com Macedo e Carrasco (2005), essa diferença, embora amplamente difundida em psicanálise, transcende uma teoria. Porém, como diz Rubem Alves (2004), parafraseando Alberto Caeiro: "Não é bastante ter ouvidos para se ouvir o que é dito. É preciso também que haja silêncio dentro da alma" (p. 67). Esse silêncio pode ser compreendido a partir do que Freud (1911/1976) chamou de abstinência. Freud só chegou à técnica da associação livre ao silenciar. Silenciou diante de Emmy Von N., que Freud atendeu de 1889 a 1890, por meio do método hipnocatártico de Breuer. Emmy, em um determinado momento, se aborreceu com suas perguntas sobre de onde tinha vindo isso ou aquilo, e pediu a ele que a deixasse falar tudo o que ela tinha a dizer. Freud já tinha se dado conta de que suas interrupções em nada ajudavam e, que por mais tediosas que pudessem ser as narrativas e repetições de sua paciente, ele tinha que ouvi-las com todos os seus minuciosos detalhes (Freud, 1895). De acordo com Figueiredo (2013), a escuta clínica psicanalítica é uma escuta do sofrimento, do padecimento do sujeito, e por ser clínica é uma escuta das dimensões inconscientes das experiências do sofrimento. A escuta não só é condição para o que se faz em psicanálise, como muitas vezes é disto que o sujeito necessita em primeira instância. Uma escuta sensível e diferenciada, sem a qual nada pode ser feito.

Neste estudo, parte-se da hipótese de que a primeira entrevista, ao levar em consideração as expectativas do paciente em relação ao que ele deseja encontrar nos atendimentos, possibilita o enriquecimento do sentido da triagem, favorecendo assim uma melhor adesão ao encaminhamento proposto. O objetivo deste estudo é analisar as expectativas das pessoas que procuram atendimento psicológico em um serviço-escola, e os possíveis efeitos dessa escuta na adesão à psicoterapia.

\section{Método}

Fez-se uso do método clínico-qualitativo (Turato, 2010), por meio da pesquisa-ação, em que o pesquisador busca, a priori, uma participação ativa e planejada, não só objetivando executar a pesquisa em si, mas atuando na transformação da realidade observada, a partir da compreensão, conhecimento e compromisso do pesquisador (Minayo, 2004).

\section{Participantes}

Foram entrevistados dez participantes adultos, sendo um do sexo masculino, inscritos em um serviço-escola localizado no interior de São Paulo, em lista de espera para triagem e elegíveis para psicoterapia no serviço. Esses participantes são da comunidade local e se inscreveram a partir de encaminhamentos diversos, indicações, ou por iniciativa própria e foram chamados seguindo a ordem de inscrição. Foram excluídos participantes que já tinham recebido intervenção psicológica, na modalidade de plantão ou psicoterapia individual.

\section{Instrumentos}

Técnica de entrevista de triagem psicológica semiestruturada a partir da entrevista clínica (Bleger, 1998), envolvendo questões referentes ao motivo da procura, queixas manifestas, latentes, breve histórico de vida, história clínica, dinâmica familiar, aspectos sociais, finalizando com uma questão referente às expectativas em relação ao atendimento. $\mathrm{O}$ momento em que os temas eram abordados variou de acordo com a dinâmica dos participantes. Neste serviço utiliza-se a técnica de triagem interventiva. Após um ano da entrevista, efetuou-se a análise documental dos prontuários dos participantes para verificar quais foram os desdobramentos depois da triagem (follow-up).

\section{Procedimentos}

Os participantes inscritos para atendimento no serviço-escola foram contatados, via telefone, pelas secretárias do serviço, que agendaram horário para triagem com a psicóloga/pesquisadora. Na recepção do Centro de Psicologia Aplicada, o participante preencheu um questionário, aplicável a todos os pacientes a serem atendidos. A entrevista foi realizada em um ou dois encontros, de acordo com a necessidade. Após a triagem foi realizado o encaminhamento para psicoterapia breve individual no próprio serviço. Na ficha de triagem, além da queixa, acrescentaram-se as expectativas do paciente e um aviso para que o estagiário que fosse atendê-lo realizasse uma interlocução com o pesquisador sobre essas expectativas. Após um ano da triagem, com base na consulta ao prontuário, verificou-se se o participante havia se mantido em atendimento e o índice de presença nas sessões. 


\section{Análise}

Os dados coletados nas entrevistas foram tratados por meio de análise de conteúdo, proposta por Bardin (2010). A análise de conteúdo consiste em uma codificação do material a partir do texto em sua forma bruta. Essa transformação é realizada segundo regras precisas que, por recorte, agregação e enumeração, possibilita que, do conteúdo, surja uma representação, um significado, um sentido e uma expressão. Utilizou-se o referencial psicanalítico para análise e discussão.

\section{Cuidados éticos}

O projeto de pesquisa foi cadastrado no SISNEP, submetido e aprovado pelo Comitê de Ética da Universidade Paulista, sob o ${ }^{\circ}$ 073-11, estando em conformidade aos requisitos de pesquisa com seres humanos. O termo de consentimento livre e esclarecido continha informações acerca da pesquisa, compromisso de sigilo e esclarecimento de procedimentos e foi apresentado e devidamente explicado pelo entrevistador.

\section{Resultados e Discussão}

Os resultados são apresentados em duas tabelas. A Tabela 1 sumariza a frequência das respostas com base nas categorias e subcategorias propostas para análise de conteúdo. Dos resultados levantados estruturam-se análise e discussão, retomando os temas prin- cipais. A Tabela 2 apresenta o número de sessões realizadas em psicoterapia breve, tempo decorrido entre triagem e início da psicoterapia, faltas e situação atual quando do encerramento da pesquisa. Esses dados foram levantados tomando como base a consulta ao prontuário depois de, no mínimo, um ano da triagem, abrindo uma discussão sobre a relação entre escuta e análise das expectativas e adesão à psicoterapia.

Por se tratar de um estudo qualitativo, a discussão dos resultados leva em conta o conteúdo das entrevistas a partir de dois eixos: a repetição dos temas e a relevância de elementos subjetivos, portanto, individuais. Vinhetas de falas dos participantes são utilizadas em alguns casos para exemplificar o tema abordado.

A queixa manifesta se refere aos motivos que dispararam a procura por atendimento psicológico. É acessada pelo sujeito no campo da consciência (OCampo, \& Arzeno, 2009) e pode ser traduzida em palavras ao entrevistador. Dos dez casos apresentados, cinco apresentaram como queixa manifesta a depressão. Esses pacientes receberam, em algum momento, tal diagnóstico por um médico. Todos estavam fazendo uso de antidepressivo. Referem sintomas compatíveis com tal diagnóstico como insônia ou hipersonia, perda ou ganho de peso significativo nos últimos meses, desânimo para as atividades cotidianas, perda de concentração, fadiga, agitação psicomotora, autodepreciação, descritos pelo DSM V (American Psychiatric Association, 2013). Não é objetivo da triagem fazer um diagnóstico para confirmar

\section{Tabela 1}

Frequência de respostas nas categorias e subcategorias propostas para a análise de conteúdo.

\begin{tabular}{lcc}
\hline Categorias & Subcategorias & $\mathrm{N}$ \\
\hline \multirow{2}{*}{ Queixa manifesta } & Depressão & 5 \\
& Ansiedade/Irritação & 3 \\
Queixa latente & Desvalorização de si & 2 \\
& Sentimento de abandono & 5 \\
Expectativas & Rigidez/Onipotência & 3 \\
& Cura da queixa manifesta & 2 \\
& Ter com quem conversar & 10 \\
\hline
\end{tabular}


Tabela 2

Número de sessões realizadas, tempo entre a triagem e o início de atendimento em psicoterapia, faltas e status atual.

\begin{tabular}{lcccc}
\hline Participante & $\begin{array}{c}\text { Tempo entre triagem e } \\
\text { psicoterapia breve }\end{array}$ & $\begin{array}{c}\text { Número de sessões em } \\
\text { psicoterapia breve }\end{array}$ & Faltas & Status \\
\hline 1 & 7 meses & 24 & 02 & Conclusão \\
2 & 7 meses & 00 & 00 & Resolução triagem \\
3 & 7 dias & 09 & 01 & Desistência \\
4 & 3 meses & 20 & 04 & Em atendimento \\
5 & 2 meses & 31 & 01 & Conclusão \\
6 & 2 meses & 30 & 02 & Enc. Externo \\
7 & 9 dias & 24 & 01 & Conclusão \\
8 & 7 dias & 22 & 04 & Conclusão \\
9 & 7 dias & 02 & 03 & Desistência \\
10 & 5 dias & 33 & 03 & Conclusão \\
\hline
\end{tabular}

se são casos de depressão, se tem comorbidades, ou ainda de que tipo de depressão se trata, se se trata de uma reativa ou de uma depressão maior. Tampouco o diagnóstico psicológico objetiva uma classificação nosológica. Mas, de qualquer forma, todos os entrevistados encontram motivos, possuem uma explicação para o sofrimento que os acomete. Embora os motivos sejam diferentes, os que se apresentaram como deprimidos apontaram para algo em comum: o luto pela perda do objeto idealizado, que será discutido posteriormente em queixa latente.

Três participantes do sexo feminino autorreferem ansiedade e irritação constantes. Apresentam em comum a insatisfação com a vida. Apontam dificuldades nas relações familiares desde crianças. Duas referem inibição e retraimento, em diferentes cenários, cada uma a sua maneira e a partir de suas histórias de vida. Uma delas sofre de uma disfunção sexual, que associa com seu retraimento.

A queixa latente está ligada aos motivos mais profundos que levaram à busca por ajuda psicológica, tem sua inscrição muitas vezes no registro inconsciente (OCampo, \& Arzeno, 2009). Cinco participantes apresentaram como queixa latente uma desvalorização de si, sentimentos de menos-valia e de não conseguirem dar conta de suas vidas. Sentimentos que não conseguem acessar claramente, mas que os acompanham desde suas relações primárias.

Dos cinco, dois buscam no olhar do outro um reconhecimento de existência e de valor, alguém que possa autorizá-los a crescer. Referem dificuldades para aprender e uma sensação de inferioridade desde crianças. Parecem ter perdido a esperança de serem amados pelo que são. Apontam para uma sensação de abandono, de solidão, de serem menos, de exclusão. Buscam agradar o outro, temem decepcionar por medo de atualizarem essas vivências. Construíram ao longo da vida um ideal de eu marcado pela submissão. Diante das frustrações que a vida coloca, descortinam para si uma morte desse ideal, o de satisfazer o outro a qualquer preço. Veem-se então frente a frente consigo mesmos. Mas se para eles a própria existência é marcada a partir do outro, o que resta quando se percebem separados desse outro? O que os garante? Veem-se incapazes de existirem por si e a partir de si.

A participante 3 trata da dificuldade da família em geral, de forma especial a mãe, de se comunicar. Parece precisar de algo que é anterior à linguagem: precisa ser olhada. Queixa-se de não encontrar dentro de si bons objetos que possam ser expostos e admirados por alguém. Fala de uma família que não conversa entre si, que pouco a vê.

A participante 7 espera amor e reconhecimento. Com voz de criança, se apresenta frágil, desamparada e só. Diz ter sido criticada pela mãe desde muito cedo, e acredita que isso gerou nela uma autodesvalorização. Casou-se várias vezes com pessoas vistas por ela como inferiores financeira e culturalmente, buscando talvez um lugar de valor, superior. Em contrapartida, parece haver também uma crença de que ela não é capaz de atrair pessoas mais interessantes e luta para transformar seus companheiros em pessoas melhores sob seu ponto de vista, o que gera profunda insatisfação. 
$\mathrm{Na}$ sua eterna insatisfação, a participante 8 parece viver uma falta perene, insuportável e necessária, sendo marcada pelo inevitável encontro com a falta. Questão central da histeria. Freud (1900), desde a interpretação dos sonhos, sublinha que o indivíduo histérico deseja é justamente que seu desejo permaneça insatisfeito. Nessa insatisfação, sente-se desvalorizada e incompleta. Segundo seu relato, "o problema de tudo foi ter nascido mulher. Não que eu não goste de ser mulher, mas não posso ser como a maioria das mulheres, fracas e sem graça. Mas como? Nascer mulher já é problema!".

Três participantes parecem sofrer a angústia do abandono. Um abandono primário ligado às primeiras relações. Sentimentos traduzidos em sintomas, quando a busca por pertencer a alguém se tornou imperativa.

Uma delas parece buscar no outro, no sexo, no uso de substâncias químicas o elo perdido com os pais. Segundo Osório (1989), a busca pelas drogas e pelo sexo na adolescência pode estar associada a uma tentativa de reeditar a relação primordial e narcísica com a mãe, a sensação de ser único e um com ela. Experiência ilusória de plenitude. Se o sujeito não experimentou isso suficientemente, busca compulsivamente essa ilusão narcísica de satisfação plena. Busca um corpo que a acomode, que a sustente, braços que a acolham. Necessidades primárias.

A participante 9 vive a angústia do luto não elaborado. A perda do marido fez com que ela se sentisse só, e estar só parece ser insuportável. Não se trata da solidão pela ausência de alguém, mas sim de estar só consigo mesma. Relata que sua mãe era uma pessoa fria e distante. Muito preocupada com os afazeres de casa e pouco afetiva. Na triagem, foi dito a ela que talvez essa fosse a forma como a mãe sabia amar, cuidando da casa, o que devia incluir cuidar dos filhos. Ela ficou pensativa. Diz ter encontrado no marido a experiência de amar e ser amada. Que se realizou com ele, teve sonhos, realizou projetos, e que ao enterrá-lo, enterrou junto suas perspectivas. Parece saber racionalmente que ele não a abandonou, mas o sentimento que ela consegue acessar é de abandono. E assim, ela abandona a si mesma. Não consegue trabalhar, sustentar vínculos, viver.

A participante $10 \mathrm{diz}$ sempre ter cuidado dos filhos e do marido. De vida simples, trabalhava e cuidava da casa. Refere um casamento difícil. Relata que o marido a agredia verbalmente, mas ela acre- ditava que o casamento só terminava com a morte, como havia prometido. Cuidou do marido doente por quatro anos, suportando suas agressões. Durante o adoecimento do marido, os dois filhos se casaram. Um deles ficou morando com ela. Depois da morte do pai ele se mudou. Ela se queixa de solidão e de ter sido abandonada pelos filhos, que pouco a visitam. Parece expressar este sofrimento através de adoecimento: dor generalizada no corpo, hipertensão, falta de ar, conseguindo assim algum olhar, algum cuidado dos filhos e das noras. Seu corpo adoecido parece atender a duas necessidades: comunicar suas angústias e aproximar seus filhos: "Basta eu melhorar, ninguém mais se lembra de mim". Ao relatar sobre suas doenças, tem uma expressão de alívio, quase um ar alegre, talvez porque encontre no sofrimento do corpo uma forma de existir para o outro, de ser olhada, de ser amada.

Duas participantes apresentaram aspectos rígidos e onipotentes. Cada uma dentro de seu cenário, de sua história. A participante 4 parece transitar entre a onipotência e a impotência, lutando desesperadamente contra as frustrações da vida. Se desespera frente ao real que se impõe. Um real que a atropela e a faz se sentir impotente. Luta contra a impotência, a perda do eu ideal, ideal narcísico de onipotência que persegue. Quando se depara com as coisas como são e se vê sem o controle das situações, desorganiza-se, descontrola-se. Não quer remédios, não quer ajuda, parece desejar sair desta situação magicamente e onipotentemente. Revela um ódio e ataca as possibilidades de ajuda. "Vim aqui porque não tem outro jeito. Mas quem precisa de terapia não sou eu. O que adianta eu me tratar se as pessoas continuam sem noção?". Na sua fantasia onipotente, deprecia o trabalho dos estagiários: "O que esses estagiários podem fazer por mim? São pessoas que estão aprendendo, e acho que eu tenho mais coisa para ensinar para eles do que eles para mim. Não sei do que vai adiantar eu vir aqui". Nesse caso, a triagem foi realizada em três encontros a fim de, através da escuta, mobilizar nela o reconhecimento da necessidade de ajuda. Esse objetivo foi alcançado, pois ela aderiu ao tratamento de forma efetiva, como será apresentado na Tabela 2 .

A participante 5 reconhece sua rigidez. Fala de uma criação rígida, sem abertura com os pais. Sofre no corpo uma severidade superegóica, sem ter com quem dividir seu conflito intenso entre o desejado e o imaginariamente proibido. 
Quanto às expectativas, todos os entrevistados afirmaram ter como expectativa primeira livrar-se de seus sofrimentos, apresentados por eles através da queixa manifesta. Freud (1913/1976) afirma: "A força motivadora primária na terapia é o sofrimento do paciente e o desejo de ser curado que deste se origina" (p. 186). Embora se saiba e Freud também afirme que esse desejo não é suficiente para manter a terapia, nesta pesquisa, se confirmou que o sofrimento e o desejo de se curar apresentam-se como motor da busca por terapia.

A partir dessa expectativa primordial, os participantes foram estimulados a dizer o que mais esperavam dos atendimentos. Dos dez, sete expressaram o desejo de ter com quem conversar. Conversar parece algo simples, possível nas relações humanas e que não necessariamente precisa de um espaço profissional para que essa atividade aconteça. Mas, como afirma Outeiral (2005), "É triste como perdemos na cidade nossa capacidade de conversar...” (p. 54). O desejo de ter um interlocutor prevalece aqui sobre as outras expectativas de forma significativa. Mas o que significa conversar em psicoterapia? Os estagiários que atenderam os participantes em psicoterapia foram orientados em relação a essa expectativa. É necessário ter bom repertório não erudito para poder conversar e, concomitantemente, um conhecimento teórico que sustente essa "conversa". Isto significa que, ao atender uma pessoa, deve-se utilizar uma linguagem que ela compreenda, evitando complexidades e teorias e, ao mesmo tempo, o conteúdo do que é dito deve estar alinhavado com um saber teórico, que não é o mesmo saber do senso comum. Pode-se dizer que a teoria funciona nos atendimentos psicológicos como o alicerce de uma casa. Ninguém o vê exposto, mas ele está lá, sustentando toda a construção. Assim é o conhecimento teórico, um sustento da escuta e das intervenções psicológicas.

A presença de um outro que, primeiro escuta e depois transforma o inominável em palavras e, com a neutralidade necessária, ajuda a transformar sentimentos em pensamentos como bem expressou um dos participantes. Possibilita a introjeção de bons objetos, a integração, e contribui para tornar tolerável o sentimento de solidão (Quinodoz, 1993). O valor de um interlocutor, de uma presença viva na construção dessa capacidade já era sinalizado por Freud (1916/1976), que, afirmando que o medo do escuro nas crianças está relacionado ao temor da solidão, relata ter ouvido de um menino com medo de escuro dizer para sua tia: "fala comigo tia, estou com medo. A tia diz: Mas de que adianta isso, você nem está me vendo. Ao que o menino responde: Mas quando alguém fala comigo a luz vem" (p. 474).

Conversar em psicoterapia não significa fazer eco ao que o sujeito diz, mas sim, e principalmente, fazer com que esse sujeito que busca por ajuda psicológica, possa se sentir compreendido naquilo que nem ele próprio compreende de si. Duas participantes manifestaram o desejo de obter respostas sobre o que fazer. Aprisionadas no outro, cada uma a sua maneira acreditavam que o psicólogo diria qual é o caminho mais certo, mais fácil e, portanto, menos sofrido.

Dos dez entrevistados, apenas um verbalizou o desejo de se conhecer melhor. Rígida e exigente, sofria no corpo, através da disfunção sexual, a contradição entre amar sexualmente e controlar-se. Parecia não se entregar para não perder o controle.

Quanto à adesão, dos dez participantes, cinco concluíram o processo de psicoterapia, um permaneceu em atendimento no próprio serviço e um foi encaminhado, depois de um ano de atendimento em psicoterapia breve, para atendimento no consultório do próprio estagiário que havia se formado. Estes dados apontam para uma significativa adesão ao processo psicoterápico a partir da escuta e análise das expectativas. $O$ participante 1 pediu uma escuta individualizada. Ele era atendido em grupo no serviço público do município, mas demandava um lugar e um alguém só para si. Em grupo, parecia reeditar a vivência primária de sua angústia: não ter um olhar materno que o privilegiasse. Permaneceu em atendimento individual durante todo ano de $2012 \mathrm{com}$ a mesma estagiária, tendo concluído o processo. Ele encontrou finalmente um lugar para existir no olhar do outro, para então poder olhar para si.

A participante 4, na terceira entrevista do processo de triagem, disse que tentaria comparecer para atendimento, mas queria alguém experiente que entendesse o que ela estava passando e que soubesse orientá-la. Por questões de funcionamento do serviço, foi atendida por uma jovem estagiária, contrariando seu pedido. $\mathrm{O}$ fato dela querer alguém mais experiente foi trabalhado na triagem, a partir de reflexões sobre seu sentimento de desamparo. Era como uma criança pedindo uma mãe. Anotações do prontuário indicam que ela aderiu efetivamente, tendo quatro faltas justificadas, permanecendo em atendimento. 
A participante 5, que sofria no corpo a contradição entre amar sexualmente e controlar-se, manifestada pela disfunção sexual, talvez não se entregasse para não perder o controle. Encontrou nos atendimentos uma possibilidade de se conhecer e se permitir entregar-se a um outro. Abrir suas questões mais angustiantes permitiram ressignificar sua capacidade de se vincular. Ficou em atendimento dois semestres, apresentando remissão de seus sintomas físicos.

Para a participante 7 , ter com quem conversar parecia trazer a esperança de ser ouvida e compreendida sem ser criticada. Foi atendida por dois semestres, faltou apenas uma vez. Concluiu o processo e segundo relatórios que constam no prontuário, houve benefícios práticos na sua vida, que ela entendeu como sendo efeitos da psicoterapia, como por exemplo, se incomodar menos com as diferenças entre ela e o marido e reconhecer seus potenciais.

A participante 8 também fez uma exigência: queria ser atendida por um homem, pois entendia que as mulheres são "rasas". Essa crença apontava para uma desvalorização do feminino, contrastando com a compreensão que ela fazia de si, a de ser uma defensora do lugar da mulher. Foi atendida por dois semestres por uma estagiária jovem, mas bem desenvolta e com excelente repertório. Não era um repertório erudito, técnico, mas sim, próximo e empático. Ela não foi atendida por um homem como gostaria, mas isso não dificultou o desenvolvimento do trabalho.

Em busca de compreensão, a participante 6 precisava de alguém que a escutasse e compreendesse, que legitimasse sua dor. Ao encontrar um interlocutor empático, a participante, que sempre desistia de tudo que fazia, aderiu efetivamente à psicoterapia e repetia constantemente à estagiária que a atendia: "é muito bom ter com quem conversar de verdade, ter alguém que escuta a gente". Foi atendida por dois semestres e encaminhada para o consultório da estagiária depois que essa se formou, o que sugere uma efetiva formação de aliança terapêutica.

Depois de um ano de atendimento, a participante 10 concluiu o processo. Participou ativamente também de grupo oferecido pela universidade organizado por uma parceria entre cursos. Dizia que não queria nunca faltar aos atendimentos, pois eram esses os momentos que ela encontrava com quem conversar. E que conversar era bom, a ajudava a organizar os pensamentos e "pensar os sentimentos".
Quando se pensa sobre o fenômeno da desistência em serviços públicos, um dos fatores a ser considerado é o tempo que a pessoa fica aguardando em lista de espera. Embora não seja possível neste estudo fazer a equivalência tempo e desistência, nota-se que os dois participantes que não aderiram não ficaram em espera entre a triagem e o início da psicoterapia propriamente dita.

A psicoterapia breve é caracterizada por um período estabelecido de atendimento psicológico, em um reduzido espaço de tempo (Fiorini, 2008). Os pacientes que concluíram o processo foram atendidos em dois semestres letivos e atingiram, em alguma medida, suas expectativas, de acordo com as anotações nos prontuários e relatórios finais. Em relação às faltas, um preditor da adesão, os pacientes que deram continuidade ao processo apresentaram um baixo índice de faltas, denotando engajamento no processo.

As desistências tiveram motivações diferentes. $\mathrm{O}$ participante 3 tinha como objetivo conseguir passar em uma entrevista de emprego. Tinha dificuldades de falar de si para alguém. Refere ter conseguido emprego depois de nove sessões, pois aprendera a se colocar com mais segurança, segundo ela. O participante 9 desistiu depois de duas sessões sem justificativa. A estagiária foi orientada a entrar em contato, mas segundo relatos não houve retorno. Vale ressaltar que, no caso desta estagiária em particular, havia uma história de desistências dos pacientes, logo no início de seus atendimentos, o talvez justifique levantar a hipótese de uma dificuldade por parte desta de estabelecer alianças terapêuticas, reforçando a importância da supervisão para o pleno desenvolvimento do trabalho executado pelos serviços-escola e um olhar, por parte do supervisor, às características pessoais e técnicas dos seus supervisionandos.

Quando a participante 2 foi chamada para psicoterapia, comunicou ao estagiário que entrou em contato com ela, que a triagem tinha sido importante e suficiente e que não precisava mais de atendimento. Disse que tinha pensado nas questões levantadas pela psicóloga/pesquisadora e tomado decisões importantes permitindo uma mudança no cenário de sua história, o que reforça a ideia de que a triagem psicológica é, por si, interventiva. Não dá para falar em desistência nesse caso, mas em uma resolução na triagem, o que abre uma discussão sobre o fenômeno da desistência. Existem situações que à primeira vista podem ser entendidas como desistência, mas, ao 
focar cada caso com a lente de uma análise psicológica que leve em conta o desejo e as expectativas, não aderir à psicoterapia pode ser inclusive terapêutico. Retomando as expectativas, esta participante buscava no outro as respostas. Parece tê-las encontrado na triagem, mas, ao internalizá-las, provavelmente se apropriou, e pode seguir em frente por conta própria. Assim, esse outro imbuído por ela com um saber $a$ priori, provavelmente tornou-se dispensável.

\section{Conclusões}

O serviço-escola no qual essa pesquisa foi realizada apresentava um índice de abandono preocupante. Embora se saiba que o processo de psicoterapia demanda tempo e, muitas vezes, tem resultados que não estão dentro do tempo e dos objetivos esperados pelas pessoas que buscam atendimento, o que pode levar à desistência ou abandono, algo precisa ser feito no sentido de identificar os motivos que levam à interrupção da psicoterapia não só em serviços-escola, mas também em outros serviços públicos e privados, já que as desistências e abandono em relação ao tratamento psicológico não são exclusividades de serviços-escola. Assim, tentar dar novos significados ao encontro entre estagiário de Psicologia e paciente, significado este que só pode ser construído na medida em que se compreenda o que a pessoa que busca atendimento psicológico espera receber.

Estar atento às expectativas pode ajudar o entrevistador a acessar o desejo inconsciente, permitindo assim uma compreensão maior e uma aproximação com o sofrimento da pessoa que busca ajuda. Escutar as expectativas não significa necessariamente satisfazê-las, mas compreendê-las, legitimá-las e auxiliar o paciente a se apropriar delas, elaborando em certa medida, o quanto é possível e necessário fazer. A triagem, por ser a porta de entrada para qualquer proposta de intervenção, é um dos momentos profícuos para dar voz às expectativas, compreendê-las e devolvê-las de forma mais clara e refletida ao entrevistado. Os dez casos apresentados traziam em si uma esperança de que, através do atendimento psicológico, poderiam ser ajudados. E foram. Os resultados mostram um índice de adesão satisfatório, e dos três que não deram continuidade, apenas um abandonou sem justificar.

Reflexões se abrem a partir deste estudo como o que diz respeito aos preditores de abandono e desistência ao atendimento psicológico, não só nos serviços-escola, mas também em outros serviços públicos e privados, e quais elementos podem favorecer a aliança terapêutica. Outro fator que merece estudo mais aprofundado diz respeito ao papel dos supervisores junto aos estagiários, a fim de que esse hiato produzido entre o ideal e o real seja amenizado. Embora esta pesquisa tenha focado o momento da triagem, o cuidado dos supervisores no que diz respeito ao incentivo e orientação dos estagiários em relação à escuta e legitimação das expectativas dos pacientes pode estar presente em outras intervenções, como a psicoterapia por exemplo, dado que é possível haver um tempo muitas vezes maior do que o esperado entre triagem e início de atendimento. Neste caso, as expectativas, as queixas, a história de vida podem ter se modificado neste espaço entre a triagem e o início dos atendimentos.

Em relação aos serviços-escola, cabe à supervisão ajudar os estagiários a lidarem com as próprias ansiedades e expectativas inerentes a esse momento singular da formação. A supervisão é um espaço privilegiado para que essas questões sejam refletidas no sentido de ajudá-los a desenvolver a arte da paciência sem almejar necessariamente resultados imediatos. O supervisor deve transmitir ensinamentos básicos, abstendo-se de induzi-los a um modelo pronto de psicoterapeuta, ajudando para que cada estagiário olhe para dentro de si em sua relação com a pessoa que ele atende e com o supervisor (Tavora, 2002), e tudo isso preservando o espaço da supervisão, garantindo que esse não se confunda com psicoterapia.

A questão da supervisão e do treinamento do supervisor é um campo muito rico, com muitos questionamentos, tarefa complexa. Em setembro de 2013, os Conselhos Regional e Federal de Psicologia e a Associação Brasileira de Ensino de Psicologia lançaram a carta de serviços sobre estágios e serviços-escola, destacando a importância da prática supervisionada. Objetivando oferecer referências sobre a formação e o exercício profissional a todos os envolvidos neste processo, professores, orientadores, coordenadores e supervisores de campo de estágio, esse documento discute a qualidade técnica dos estágios, esclarecendo o papel de cada membro envolvido neste processo, reafirmando a influência da formação no exercício profissional, e reconhece a responsabilidade do psicólogo supervisor pela aplicação adequada de métodos e técnicas psicológicas, respeito à ética 
profissional e pelo serviço de qualidade à população. Além da publicação supracitada, a importância da formação e credenciamento de supervisores tem sido alvo de outros estudos, dentre os quais pode-se citar um, que enumera algumas instituições de acreditação de supervisores, em países como Austrália, Inglaterra e Portugal (Oliveira-Monteiro, Herzberg, Oliveira, \& Silvares, 2014).

É nesse espaço de supervisão que a escuta das expectativas pode ser articulada com a história de vida, história clínica, com desejos e fantasias inconscientes, com as queixas manifestas e latentes, e só então ser enriquecida de sentido, possibilitando que o estagiário, ao compreendê-las, auxilie seu paciente a ser inteiramente o portador de seus desejos, ainda que esses não possam ser satisfeitos

\section{Referências}

Alves, R. (2004). Escutatória. In R. Alves, O amor que ascende a lua (pp. 65-71). Campinas, SP: Papirus.

American Psychiatric Association. (2013). Manual diagnóstico e estatístico de transtornos mentais: DS$M-V$. Porto Alegre, RS: Artmed.

Ancona-Lopez, S. (1996). A porta de entrada: da entrevista de triagem à consulta psicológica (tese de doutorado). Pontifícia Universidade Católica de São Paulo, São Paulo.

Ancona-Lopez, S. (2005). A porta de entrada: reflexões sobre a triagem como processo interventivo. In C. P. Simon, L. L. Melo-Silva, \& M. A. Santos (Orgs.). Formação em Psicologia: serviços-escola em debate (pp. 259-270). São Paulo, SP: Vetor.

Ancona-Lopes, M. (1981). Avaliação de serviços de psicologia clínica (dissertação de mestrado). Pontifícia Universidade Católica de São Paulo, São Paulo.

Bardin, L. (2010). Análise de conteúdo. Lisboa: Ed. 70.

Barbieri, V. (2008). Por uma ciência-profissão: o psicodiagnóstico interventivo com o método de investigação científica. Psicologia em Estudo, 13(3), 575-584. doi:10.1590/S1413-73722008000300019

Benetti, S. P. C. \& Cunha, T. R. S. (2008). Abandono de tratamento psicoterápico: implicações para a prática clínica. Arquivos Brasileiros de Psicologia, 60(2), 48-59. Recuperado de http://pepsic. bvsalud.org/scielo.php?script=sci_arttext\&pi$\mathrm{d}=$ S1809-52672008000200007 inteiramente. Não é possível afirmar que a escuta das expectativas seja o único fator a promover uma maior adesão ao encaminhamento proposto. Mas é possível pensar que a escuta e compreensão dessas expectativas possibilitam que questões possam ser colocadas e algo efetivo possa ser realizado. Esse algo tem relação com o sentido dado às expectativas, uma aproximação entre o que pode ser feito em psicoterapia e o que espera legitimamente o paciente em relação ao seu atendimento. E é no espaço da supervisão, mediado pela escuta atenta do supervisor aos relatos do supervisionando e às suas angustias e ansiedades, que o hiato entre as expectativas de um e outro pode encontrar possibilidades de ser amenizado.

Bleger, J. (1998). Temas de psicologia: entrevista e grupos. São Paulo, SP: Martins Fontes.

Bueno, H. A., Cordoba, J. A., Escolar, P. A., Carmona, C. A., Rodrigues, G. C., (2001). El abandono terapêutico. Actas Espain Psiquiatria, 29(1), 33-40.

Campezatto, P., \& Nunes, M. L. (2007). Atendimentos em clínica-escola depsicologia da região metropolitana de Porto Alegre. Estudos de Psicologia (Campinas), 24(3), 363-374. doi:10.1590/S0103-166X2007000300008

Figueiredo, L. C. (Locutor). (2013). As escutas da psicanálise. São Paulo: Sociedade Brasileira de Psicanálise de São Paulo. Áudio recuperado em 20 jan 2014, de http://www.youtube.com/watch?v=U87JX4D7gZ4

Fiorini, H. J. (2008). Teoria e técnicas de psicoterapias. (2a ed, trad. M. S. Gonçalves). São Paulo, SP: Martins Fontes.

Freud, S. (1976). Interpretação dos Sonhos. In Edição standard brasileira das obras psicológicas completas de Sigmund Freud (J. Salomão, trad., Vols. IV e V, pp. 1-761). Rio de Janeiro, RJ: Imago. (Trabalho original publicado em 1900).

Freud, S. (1976). Conferências introdutórias sobre psicanálise. In Edição standard das obras psicológicas completas de Sigmund Freud (J. Salomão, trad., Vol. 16, pp. 289-559). Rio de Janeiro, RJ: Imago. (Trabalho original publicado em 1916).

Freud, S. (1976). O manejo da interpretação de sonhos na psicanálise. In Edição Standard Brasileira das Obras Psicológicas Completas de Sigmund Freud (J. Salomão, trad., Vol. 12, pp. 119-127). Rio de Janeiro, RJ: Imago. (Trabalho original publicado em 1911). 
Freud, S. (1976). Sobre o início do tratamento. In Edição standard das obras psicológicas completas de Sigmund Freud (J. Salomão, trad., Vol. 18, pp. 164-187). Rio de Janeiro, RJ: Imago. (Trabalho original publicado em 1913).

Freud, S. (1976) Sobre o mecanismo psíquico dos fenômenos histéricos: comunicação preliminar. In: Edição standard das obras psicológicas completas de Sigmund Freud (J. Salomão, trad., Vol. 2, pp. 41-60). Rio de Janeiro, RJ: Imago. (Trabalho original publicado em 1895).

Garfield, S. (1989). Giving up on child psychotherapy: who drops out? Comment on Weisz, Weiss and Langmeyer. Journal Consult Clinical Psychology, 55(6), 168-169.

Guerrelhas F. F., \& Silvares, E. F. M. (2000). Grupos de espera recreativos: proposta para diminuir o índice de evasão em clínica-escola de psicologia. Temas de Psicologia, 8(3), 313-321. Recuperado de http:// pepsic.bvsalud.org/scielo.php?script=sci_arttext\&pid=S1413-389X2000000300009

Herzberg, E., \& Chammas D. (2009). Triagem estendida: serviço oferecido por uma clínica-escola de Psicologia. Paideia (Ribeirão Preto), 19(42), p. 107-114. doi:10.1590/S0103-863X2009000100013

Lhullier, A., Nunes, M. L, \& Horta, B. (2006). Preditores de abandono de psicoterapia em pacientes de clinica-escola. In E. Silvares (Org.), Atendimento psicológico em clinicas-escola (pp. 229-256). Campinas, SP: Alinea.

Macedo, M. M. K., \& Carrasco, L. K. (2005). A entrevista clínica: um espaço de intersubjetividade. In (Con)textos de entrevistas: olhares diversos sobre a interação humana (p. 26). São Paulo, SP: Casa do Psicólogo.

Macedo, M. M. K., \& Falcão, C.N.B. (2005). A escuta na psicanálise e a psicanálise da escuta. Psychê, 9(15), 65-76. Recuperado de http:// pepsic.bvsalud.org/scielo.php?script=sci_arttext\&pid=S1415-11382005000100006

Maramba G. G., \& Hall, G. C. N. (2002). Meta-analyses of ethnic match as a predictor of dropout, utilization, and level of functioning. Cultural Diversity \& Ethnic Minority Psychology, 8(3), 290-7.

Melo, A. P. S., \& Guimaraes, M. D. C. (2005). Fatores associados ao abandono do tratamento psiquiátrico em um centro de referência em saúde mental de Belo
Horizonte. Revista Brasileira de Psiquiatria, 27(2), 113-118. doi:10.1590/S1516-44462005000200008

Melo-Silva, L. L., Santos, M. A., \& Simon, C. P. (Orgs.). (2005). Serviço-escola em psicologia: a construção do saber prático. In L. L. Melo-Silva, M. A. Santos, \& C. P. Simon. (Orgs), Formação em psicologia serviços-escola em debate (p. 21-30). São Paulo, SP: Vetor.

Merg, M. M. G. (2008). Características da clientela infantil em clínica-escola (dissertação de mestrado). Faculdade de Psicologia da Pontifícia Universidade Católica do Rio Grande do Sul, Porto Alegre, RS.

Milagre, I. M. S., \& Dias, A. G. (2012). Abandono do tratamento na clínica-escola do UNIPAM: Reflexões institucionais. Perquirere, 9(1), 55-69. Recuperado de http://perquirere.unipam.edu.br/documents/23456/55708/abandono.pdf

Minayo, M. C. S. (2004). O desafio do conhecimento: pesquisa qualitativa em saúde (8a ed.). São Paulo, SP: Hucitec.

Morato, H. T. P., Andrade, A. N., Vieira Filho, N. G., Cury, V. E., Ancona-Lopez, S., Szymansky H., ... Ayello-Vesberg, T. M. J. (2002). Práticas psicológicas em instituições: atenção desconstrução e invenção. In Coletâneas ANPEEP do 8o Simpósio Brasileiro de Pesquisa e Intercâmbio Científico (pp. 195-205). Serra Negra, SP.

Ocampo, M. L. S., \& Arzeno, M. E. G. (2009). A entrevista inicial (M. Felzenszwalb, trad.). In M. L. S. Ocampo, M. E. G. Arzeno, E. G. Piccolo, \& cols., O processo psicodiagnóstico e as técnicas projetivas (11a ed., pp. 15-46). São Paulo, SP: Martins Fontes.

Oliveira-Monteiro, N. R., Herzberg, E., Oliveira, M. S., \& Silvares, E. F. M. (2014). Reflexões sobre ética na supervisão em psicologia. Boletim de Psicologia, 63(139), 217-225. Recuperado de http://pepsic.bvsalud.org/scielo.php?script=sci_arttext\&pi$\mathrm{d}=$ S0006-59432013000200009

Outeiral, J. (2005). Conhece-te a ti mesmo. São Leopoldo, RS: Editora Unisinos.

Osório, L. C. (1989). Adolescente hoje. Porto Alegre, RS: Artmed.

Peres, V.L.A. (1997). Triagem psicológica grupal: procedimento e resultados obtidos com lista de espera de crianças, adolescentes e adultos, em uma clínica-escola de psicologia. Paidea (Ribeirão Preto), 11(13), 63-76. doi:10.1590/S0103-863X1997000100006 
Perfeito, H.C.C.S., \&Melo, S.A. (2004).Evolução do processo de triagem psicológica em uma clínica-escola. Estudos de Psicologia (Campinas), 21(1), 33-42. doi:10.1590/S0103-166X2004000100003

Quinodoz, J.-M. (1993). A solidão domesticada (F. F. Settineri, trad.). Porto Alegre, RS: Artes Médicas.

Renk, K., \& Dinger, T. M. (2002). Reasons for therapy termination in a university psychology clinic. Journal of Clinic Psychology, 58(9), 1173-1181. doi:10.1002/jclp.10075

Rocha, M. C. (2011). Plantão psicológico e triagem: aproximações e distanciamentos. Revista do NUFEN, 3(1), 119-134. Recuperado de http://pepsic. bvsalud.org/scielo.php?script=sci_arttext\&pi$\mathrm{d}=\mathrm{S} 2175-25912011000100007$

Romaro, R. A., \& Capitão, C. G. (2003). Caracterização da clientela da clínica-escola de psicologia da Universidade São Francisco. Psicologia Teoria e Prática, 5(1), 111-121. Recuperado de http://editorarevistas. mackenzie.br/index.php/ptp/article/view/1185/883

Salinas, P., \& Santos M. A. (2002). Serviço de triagem em clínica escola de psicologia: a escuta analítica em contexto institucional. Psychê, 6(9), 177-196. Recuperado de http://www.redalyc.org/articulo. oa?id=30700914

Silvares, E. F. M. (1998). Clínicas-escola: novas formas de atendimento psicológico (tese de livre docência). Instituto de Psicologia, Universidade de São Paulo, São Paulo.

Tavora, M. T. (2002). Um modelo de supervisão clínica do estudante de psicologia: a experiência da UFC. Psicologia em Estudo, 7(1), 121-130. doi:10.1590/S1413-73722002000100015
Turato, E. R. (2010). Tratado da metodologia da pesquisa clínico-qualitativa. (4a ed.) Rio de Janeiro, RJ: Vozes.

\author{
Rita Aparecida Nicioli Cerioni \\ Mestre. Docente da Universidade Paulista, Jundiaí - \\ SP. Brasil. \\ E-mail: ritacerioni@usp.br \\ Eliana Herzberg \\ Livre-Docente da Universidade de São Paulo, São \\ Paulo - SP. Brasil. \\ E-mail: eherzber@usp.br \\ Endereço para envio de correspondência: \\ Universidade Paulista, Conselho Superior de Ensino, \\ Pesquisa e Extensão. Av. Armando Giassetti, 577. CEP: \\ 13214-525. Vila Hortolândia. Jundiaí - SP. Brasil.
}

Recebido 08/10/2014

Aprovado 21/07/2016

Received 08/10/2014

Approved 21/07/2016

Recibido 08/10/2014

Aceptado 21/07/2016

Como citar: Cerioni, R. A. N., \& Herzberg E. (2016). Expectativas de pacientes acerca do atendimento psicológico em um serviço-escola: da escuta à adesão. Psicologia: Ciência e Profissão, 36(3): 597-609. doi:10.1590/1982-3703001402014

How to cite: Cerioni, R. A. N., \& Herzberg E. (2016). Patient's expectations regarding psychological care in psychological clinics: from listening to engaging. Psicologia: Ciência e Profissão, 36(3): 597-609. doi:10.1590/1982-3703001402014

Cómo citar: Cerioni, R. A. N., \& Herzberg E. (2016). Expectativas de pacientes sobre la atención psicológica del servicio escuela: de la escucha a la adhesión. Psicologia: Ciência e Profissão, 36(3): 597-609. doi:10.1590/1982-3703001402014 